\title{
Mídias sociais como estratégia no ensino
}

\author{
em fisioterapia
}

\section{Social media as a strategy in teaching physiotherapy \\ Medios sociales como estrategia en la enseñanza \\ en fisioterapia}

\author{
Valéria Marques Ferreira Normando \\ Universidade do Estado do Pará (Uepa), Belém/PA - Brasil \\ José Maria Furtado Junior \\ Universidade do Estado do Pará (Uepa), Belém/PA - Brasil \\ Robson José de Souza Domingos \\ Universidade do Estado do Pará (Uepa), Belém/PA - Brasil \\ Isalice Rêgo Furtado \\ Universidade do Estado do Pará (Uepa), Belém/PA - Brasil
}

\begin{abstract}
Resumo
Inúmeras ferramentas da Internet estão disponíveis para o ensino em saúde. A falta de conhecimento sobre como usá-las coloca os professores sob julgamento quanto à capacidade de se adaptarem a esse novo contexto. $O$ objetivo do estudo foi identificar o uso das mídias sociais no ensino em fisioterapia na Universidade do Estado do Pará (Uepa). Trata-se de pesquisa qualitativa, realizada por meio de questionário semiestruturado, que envolveu 53 professores do curso de fisioterapia de Belém e Santarém. Após a análise de conteúdo, identificaram-se fatores que dificultam o uso das mídias sociais no compartilhamento de conhecimentos: acesso institucional restrito às redes sociais e pouca capacitação para utilização no ensino pelos professores mais experientes.
\end{abstract}

Palavras-chave: Formação de professores, Fisioterapia, Desenvolvimento educacional, Docência, Ensino superior

\begin{abstract}
Numerous Internet tools are available for health education. Lack of knowledge how to use them puts teachers under judgment as to their ability to adapt themselves to this new context. The objective of the study was to identify the use of social media in education in physiotherapy in the Pará State University (UEPA). The research was qualitative, through semi-structured questionnaire, involving 53 teachers of Belém and Santarém Physical Therapy Course. After content analysis, identifying factors that handicap the use of social media on knowledge sharing: institutional access restricted to social networks and little training teaching by the more experienced teachers.
\end{abstract}

Keywords: Teacher training, Physiotherapy, Educational development, Teaching, Higher education 


\section{Resumen}

Muchas herramientas de Internet están disponibles para la enseñanza en salud. La falta de conocimiento sobre cómo usarlas coloca a los profesores bajo juicio en cuanto a la capacidad de adaptarse a ese nuevo contexto. El objetivo del estudio fue identificar el uso de los medios sociales en la enseñanza en fisioterapia en la Universidad del Estado de Pará (UEPA). La investigación fue cualitativa, a través de cuestionario semiestructurado, con la participación de 53 profesores del curso de fisioterapia de Belém y Santarém. Tras el análisis del contenido, se identificaron los factores que dificultan el uso de los medios sociales en el intercambio de conocimientos: acceso institucional restringido a las redes sociales y poca capacitación para el uso en la enseñanza por los profesores más experimentados.

Palabras clave: Formación de profesores, Fisioterapia, Desarrollo educativo, Docencia, Enseñanza superior

\section{Introdução}

O professor formado no contexto tradicionalista precisa se adaptar à nova realidade, buscando um novo olhar e novas atitudes na formação do novo profissional fisioterapeuta, devendo ser um reconstrutor do conhecimento, não somente do ponto de vista da ciência ou da tecnologia, mas também da humanização na educação. Para o alcance dessas metas, as metodologias ativas aparecem como ferramentas estratégicas de mudança, as quais compreendem a complexidade do processo ensino-aprendizagem, assim como seu caráter dinâmico, facilitando a aprendizagem significativa e a real apreensão dos conceitos fundamentais ao ensino em saúde (GOMES; REGO, 2011).

Aliada a essas transformações, na última década, houve uma explosão do número de ferramentas disponíveis para melhorar o ensino em saúde. Com a facilidade de acessar e se conectar a mídias sociais, um novo perfil de aluno se formou. Segundo Vozenilek et al.(2004), a proliferação de computadores pessoais, a capacidade de acesso fácil à Internet e a utilização de redes sociais, blogs, podcasts e sites de compartilhamento de mídias se combinaram para alterar a natureza do ensino. A rapidez na publicação de novas informações em revistas e as postagens de multimídias com alta qualidade de fotos, filmes ou arquivos de áudio facilitaram o acesso ao conhecimento e à contextualização, proporcionando mudanças na rotina do processo ensinoaprendizagem, corroborando Probst, Raub e Romhardt (2009), segundo os 
quais o compartilhamento de conhecimento é o processo que tem como pressuposto básico a transformação de informações e experiências isoladas em algo que todos possam utilizar.

Ao mesmo tempo, há indícios de que os professores não têm utilizado essas tecnologias na mesma medida em que os alunos (IVALA; GACHAGO, 2012), seja pela crença de que as mídias sociais não melhoram o desempenho no estudo, seja pela dificuldade de uso entre os professores mais experientes na profissão. Isso significa que alunos e professores vivem em realidades diferentes, e esses estão sob considerável pressão social para melhorar a qualidade do ensino em saúde. A eficiência do método tradicional de ensino está em julgamento. Para resolver essa questão, o professor precisa explorar inovadoras formas de ensino, em particular, promovendo o envolvimento dos alunos, estimulando a tomada de iniciativa, a automotivação e o senso crítico, reforçando a sua aprendizagem (HANSON et al., 2011).

Diante das questões norteadoras apontadas, este estudo se caracterizou pela importância de identificar como os professores do curso de fisioterapia da Uepa estão se adaptando a essa nova realidade e como compartilham conhecimentos com seus pares e alunos, listando suas dificuldades, desenhadas a partir do incremento dos produtos da Internet no dia a dia do ensino universitário.

\section{Trajetória da pesquisa}

Os participantes da pesquisa foram 53 professores fisioterapeutas que lecionavam no curso de fisioterapia da Universidade do Estado do Pará, dos quais 36 estavam lotados no campus de Belém, e 17, no de Santarém.

Foi utilizado um instrumento com oito perguntas abertas, elaborado pelos autores da pesquisa, reproduzindo seus objetivos, caracterizando o processo ensino-aprendizagem e o compartilhamento do conhecimento e identificando se utilizam as ferramentas da Internet entre seus pares e alunos.

Tal instrumento recebeu análise e parecer de dois professores doutores vinculados à Associação Brasileira de Ensino em Fisioterapia (Abenfisio), levando-se em consideração a expertise e qualificação deles na referida temática. Os professores traçaram comentários e observações quanto à 
composição das questões, o que resultou na reestruturação do instrumento, tendo em vista os objetivos propostos.

O desenho metodológico foi realizado em três fases:

Fase 1-Encaminhado o Projeto ao Comitê de Ética da Uepa. Após aprovação, o corpo docente do curso de graduação em fisioterapia da Uepa foi recrutado por meio de solicitação oficial ao Departamento de Ciências do Movimento Humano (DCMH), o qual disponibilizou os nomes e titulação dos docentes. Em seguida, todos os professores foram contatados, e os que aceitaram participar da pesquisa autorizaram a coleta dos dados por meio da assinatura do Termo de Consentimento Livre e Esclarecido (TCLE).

Foram incluídos na pesquisa todos os docentes que aceitaram participar e que estavam no exercício legal de suas funções. Foram excluídos da análise aqueles que não tinham nenhum vínculo funcional com a Uepa ou que estavam em gozo de licença de qualquer caráter, em férias ou em qualquer outra forma de liberação de suas funções de forma oficiosa, no período de aplicação do questionário.

Em seguida, foi agendada a aplicação dos questionários com os professores.

Fase 2 - A coleta foi realizada nos complexos dos campi da Uepa de Belém e Santarém, durante os meses de janeiro, fevereiro e março de 2017. Foi realizada de forma individual, e o tempo médio da aplicação de cada instrumento foi de 25 minutos.

O pesquisador teve participação direta ou não, e interferiu, quando solicitado, para esclarecer dúvidas quanto ao entendimento de cada uma das questões (CANZONIERI, 2011).

Fase 3 - Foi realizada a análise das respostas, dando prosseguimento a uma segunda releitura e análise, pelo pesquisador, das informações coletadas.

Para identificar como os professores compartilham conhecimentos, foi aplicada aos dados coletados a análise de conteúdo temática, segundo a linha de Bardin (2016), que valoriza os significados presentes nos dados, sua correlação com as questões formuladas e a articulação com o marco teórico adotado na pesquisa, que permite a divisão do texto em alguns temas principais. 
A análise de conteúdo, enquanto método, é um conjunto de técnicas de análise das comunicações, que utiliza procedimentos sistemáticos e objetivos de descrição do conteúdo das mensagens (BARDIN, 2016).

Quanto ao método e técnica da análise de conteúdo referente ao compartilhamento de conhecimentos, as respostas das entrevistas passaram por organização da análise, codificação de resultados, categorizações, inferências e, por fim, informatização da análise das comunicações. Para uma aplicabilidade coerente do método, de acordo com os pressupostos de uma interpretação das mensagens e dos enunciados, a análise de conteúdo deve ter como ponto de partida uma organização. As diferentes fases se organizam em torno de três polos, conforme Bardin (2016): pré-análise, exploração do material, tratamento dos resultados, inferência e interpretação.

Porém, a autora afirma que o conceito não é suficiente para definir a especificidade da técnica, acrescentando que a intenção é a inferência de conhecimentos relativos às condições de produção, inferência essa que ocorre com indicadores quantitativos ou não. Dessa maneira, a análise de conteúdo não deve ser extremamente vinculada ao texto ou à técnica, num formalismo excessivo que prejudique a criatividade e a capacidade intuitiva do pesquisador, nem tão subjetiva a ponto de impor as ideias ou valores desse profissional, passando o texto a funcionar meramente como confirmador desses conceitos. Outro ponto importante, ainda dentro dos conteúdos, é que eles tendem a ser valorizados à medida que são interpretados, levando-se em consideração o contexto social e histórico no qual foram produzidos (GOMES CAMPOS, 2004).

A análise de conteúdo, como conjunto de técnicas, se vale da comunicação como ponto de partida, é sempre feita a partir da mensagem e tem por finalidade a produção de inferências (BARDIN, 2016).Produzir inferências sobre o texto objetivo é a razão de ser da análise de conteúdo. Confere ao método relevância teórica, implicando pelo menos numa comparação, em que a informação puramente descritiva sobre o conteúdo é de pouco valor.

Produzir inferência em análise de conteúdo significa não somente produzir suposições subliminares acerca de determinada mensagem, mas 
embasá-las com pressupostos teóricos de diversas concepções de mundo e com as situações concretas de seus produtores ou receptores (BARDIN, 2016).

\section{Resultados e discussão}

Como resultado das etapas de pré-análise, exploração do material e tratamento dos resultados, inferência e interpretação dos dados, foram identificados dois grandes temas: novas metodologias e o processo ensinoaprendizagem. $O$ processo de formação de profissionais de saúde esteve, desde muito cedo, ligado à convivência entre mestres e aprendizes, num processo denominado aprendizagem. Segundo Ariès (2006), a aprendizagem representou importante atividade educacional na Europa medieval desprovida de escolas, onde alguns elementos das metodologias ativas poderiam ser identificados: o estudante ou a aprendiz não recebia o conhecimento de forma unidirecional, participando ativamente com o mestre na sua produção.

A modernização flexneriana transformou o tradicional processo de aprendizagem do ensino médico, ao deslocar o ensino dos ambulatórios, enfermarias e domicílios dos doentes para as salas de aulas e laboratórios. Suas propostas vieram ao encontro das necessidades de resolver inúmeros problemas relacionados à educação médica da época, melhorando a padronização do ensino, criando uma cultura universitária no ensino médico e estimulando a certificação das escolas por órgãos governamentais ou privados (GOMES; REGO, 2011).

Porém, após três décadas das reformas oriundas do Relatório Flexner, surgiram contestações quanto à eficiência da formação teórica, fragmentada e especializada, culminando com a criação da metodologia ativa de ensinoaprendizagem conhecida como Problem Based Learning (PBL), no Canadá. Trata-se de um método centrado no aluno, partindo do seu conhecimento prévio e instigando sua curiosidade e criatividade, objetivando promover a aprendizagem significativa.

As Diretrizes Curriculares Nacionais (DCN) de 2002 transformaram a formação do fisioterapeuta, colocando-o como agente reflexivo, crítico, participativo na construção do conhecimento, e estimularam as Instituições de Ensino Superior (IES) a se adaptarem a essa nova realidade. O novo 
profissional deverá desenvolver habilidades peculiares à sociedade em que está inserido, considerando-se que a educação superior não tem como objetivo somente a instrução e a capacitação profissional, devendo assegurar, ainda, a capacidade de lidar com a rapidez da circulação das informações e o uso das tecnologias de informação e comunicação (TIC) como instrumento de auxílio na gestão e educação permanente. Existem dificuldades no processo de formação para estimular a construção de um profissional competente, que alie as habilidades necessárias à prática médica, levando-se em conta a relação entre os elementos psicológicos, sociais, históricos e ambientais (GOMES; REGO, 2011).

Portanto, a implantação de uma nova visão metodológica pede uma grande reestruturação da prática do ensino aplicada até agora. É preciso sair do modelo burocrático de uma educação fragmentada, tecnicista, e evoluir para um ensino de práticas médicas ético-humanísticas, garantindo ao paciente uma compreensão melhor de seu problema.

O professor formado no contexto tradicionalista precisa se adaptar à nova realidade, buscando um novo olhar e novas atitudes na formação do novo profissional fisioterapeuta preconizado pelas DCN 2002. Elas pontuam que 0 professor deve ser um reconstrutor do conhecimento, não somente do ponto de vista da ciência ou da tecnologia, mas também da humanização na educação (GOMES; REGO, 2011). Para alcançar essas metas, as metodologias ativas aparecem como ferramentas estratégicas para essa mudança, pois compreendem a complexidade do processo ensino-aprendizagem como também seu caráter dinâmico, facilitando a aprendizagem significativa e a real apreensão dos conceitos fundamentais ao estudo da medicina.

Nas falas dos participantes da pesquisa, notou-se entre os professores, tanto de Belém quanto de Santarém, uma mudança nesse sentido. Ela foi implantada pela gestão do curso e pela necessidade de cada um deles de buscar novas ferramentas de auxílio ao processo ensino-aprendizagem, conforme as falas a seguir:

Utilizo como estratégias as diversas formas de metodologia ativa, sem deixar de mesclá-las com estratégia tradicional de estudo e discussão de artigos científicos. (PB 09) 
Hoje, uso as metodologias ativas como PBL e TBL, metodologia mais dinâmica que permite que tanto ao professor como ao aluno aprofundem mais seus conhecimentos. (PB 13)

Aula expositiva tradicional, considero efetiva para alguns conteúdos, porém requer tempo suficiente e recursos didáticos inovadores. Metodologia ativa, $\mathrm{PBL}$, considero bastante efetiva e estimulante para os acadêmicos, no que diz respeito tanto ao aprendizado, quanto à produção. (PS 03)

Há de se ressaltar que, mesmo tendo uma formação inicial segundo o modelo tradicionalista de ensino, muitos professores reconhecem que as metodologias ativas facilitam a construção de um novo profissional fisioterapeuta, estimulando a busca do conhecimento, a autonomia intelectual e o compartilhar do conhecimento construído por meio de grupos de trabalho na busca de conteúdos, conceitos e habilidades cognitivas.

\section{Compartilhamento de conhecimento entre pares e discentes}

A universidade é um amplo espaço de apresentação de ideias, compartilhamento de conhecimento, aprendizagem e criação de valor. Os professores têm, no conhecimento, um patrimônio e, ao mesmo tempo, um grande desafio. O conhecimento desenvolvido e adquirido pelos professores é trazido para discussão em sala de aula, por meio da exposição de ideias, discussão de artigos, leitura de livros, produzindo novos conhecimentos pela interação com os discentes. Nas instituições de ensino, o conhecimento não é apenas fundamental, ele é a própria instituição. $O$ desafio se apresenta quando há dificuldades no compartilhamento entre professores ou entre eles e os alunos (SCHARF, 2008).

Compartilhamento do conhecimento é o processo que tem como pressuposto básico a transformação de informações e experiências isoladas em algo que todos possam utilizar (PROBST et al., 2009). Após o conhecimento ter sido mapeado, adquirido e organizado, ele deve ser compartilhado (LEITE; COSTA, 2007). Portanto, o professor é mais que um mediador; é, antes, um organizador do conhecimento e da aprendizagem. Assim como os alunos precisam construir e reconstruir o conhecimento a partir do que fazem, também o professor precisa ser curioso, buscar sentido no que faz e apontar novos sentidos para o que fazer. Se docentes e estudantes 
compartilham conhecimento de forma organizada e contínua, a possibilidade de aprendizagem é maior (GADOTTI, 2008).

As pessoas estão inseridas na sociedade por meio de relações, que começam no âmbito familiar, escolar, na comunidade em que vivem. Essas relações desenvolvidas é que mantêm e fortalecem a esfera social.

A partir do desenvolvimento dos meios de comunicação, principalmente depois da Internet, as relações sociais prescindem do espaço físico e geográfico; elas ocorrem independentemente do tempo e/ou do espaço no qual se constituem e proliferam de acordo com a essência da informação e do conhecimento, uma vez que são eles que movimentam as redes.

O conceito de redes sempre pressupõe agrupamentos; elas são fenômenos coletivos, e sua dinâmica implica no relacionamento de grupos, pessoas, organizações ou comunidades, denominados atores. Possibilitam diversos tipos de relações - de trabalho, de estudo, de amizade, entre outros. As redes sociais constituem uma das estratégias subjacentes utilizadas para compartilhar informação e conhecimento mediante relações entre os atores que as integram, nas quais cada um tem sua função e identidade cultural, e a sua relação com outros indivíduos forma um todo coeso, o que representa a rede (TOMAÉL; ALCARÁ; DI CHIARA, 2005).

De forma crescente, muitas pessoas estão conectadas em rede através das mídias sociais, as quais são definidas como mídias on-line e que têm por característica encorajar a discussão, votação, comentários e compartilhamento de informações em todos os âmbitos de interesses dos indivíduos (BAHNER et al., 2012).

Para ser mais eficiente, o compartilhamento do conhecimento e da informação em rede requer a adoção de uma postura de cooperação, em que os atores utilizem múltiplos recursos, valorizando tanto o contato pessoal quanto o uso de tecnologia como ferramenta de comunicação, culminando no aprendizado. Segundo Tomaél, Alcará e Di Chiara (2005), a aprendizagem é promovida pelo compartilhamento e pelo uso da informação, os quais, como resultado, possibilitam novos aportes, entre eles, os novos conhecimentos e novas habilidades. 
O ensino tem sido claramente alterado pelas mídias sociais. Essa tecnologia ultrapassou os métodos tradicionais de fornecimento de educação, e os educadores se encontram à procura de novas maneiras de oferecer conhecimentos. Como o ensinar os afasta da sala de aula para o aprendizado on-line, os professores terão que ser capazes de navegar em novas tecnologias para alcançar seus alunos. A educação está disponível on-line para todos. Professores e alunos tradicionais estão desempenhando papéis diferentes, em que aqueles são mais facilitadores do que didatas, e esses muito mais ativos no processo de ensino-aprendizagem (BAHNER et al., 2012).

A mídia social na educação médica representa um novo paradigma pedagógico. Ela tem feito parte da vida moderna, permitindo que milhões mantenham contato uns com os outros, possibilitando aos indivíduos criar e publicar conteúdo a qualquer hora. Professores da área de saúde sempre tiveram a tarefa de preparar os estudantes de hoje para a prática de amanhã, mas nunca precisaram associar as inúmeras abordagens on-line à aprendizagem tradicional. Docentes deveriam facilitar o uso das mídias sociais no ensino médico, trabalhando com os alunos na potencialidade máxima que as mídias sociais oferecem para a facilitação da aprendizagem (HILLMAN; SHERBINO, 2015).

As mídias sociais representam uma grande promessa no processo ensino-aprendizagem, colaborando com a interação, melhorando a experiência de aprendizagem dos alunos por meio da personalização das páginas, fornecendo ricas oportunidades de networking (rede de relacionamento) e, acima de tudo, representam um processo de aprendizado centrado no aluno, que estará à frente de postagens, comentários ou discussões (HILLMAN; SHERBINO, 2015).

Como exemplos de mídias sociais, temos Facebook, Twitter, Instagram, blogs, Edmodo, podcasts e assim por diante. O Facebook, por exemplo, pode ser utilizado como instrumento para divulgação de cursos, compartilhamento de conhecimentos, troca de experiências acadêmicas, melhorando a comunicação entre alunos e professores. O uso de blogs (site alimentado em ordem cronológica das postagens) funciona como um diário on-line. Pode ser escrito pelo professor ou por um grupo de alunos, tornando o material a ser 
compartilhado acessível para posterior reflexão e análise. Blogs podem reunir pequenos grupos virtuais de pessoas interessadas na construção do conhecimento em torno de um tema comum (IVALA; GACHAGO, 2012).

Os professores entrevistados afirmaram que gostam de trabalhar como docentes e acreditam que o uso das ferramentas da Internet possa melhorar o aprendizado. Porém, o acesso limitado à rede mundial de computadores dentro da instituição - tanto pela cobertura disponível somente em locais específicos, como a biblioteca, quanto pela restrição de navegação, impossibilitando o acesso às mídias sociais - é um fator desestimulante para o seu uso no ensino.

Os portais de universidades são os mais utilizados (84,90\%), seguidos de teleconferências $(79,24 \%)$ e e-mail $(7,35 \%)$, esses caracterizados como mídias institucionais (Figura 1).

As mídias sociais são pouco utilizadas. As citadas pelos professores são o Facebook, utilizado por $28,30 \%$ deles, o Instagram e o Edmodo, utilizados por $13,20 \%$ dos docentes, e o Twitter, utilizado somente por $7,54 \%$ deles.

$\mathrm{O}$ aplicativo de mensagens instantâneas WhatsApp é bem difundido entre os professores, sendo utilizado por $69,81 \%$ deles, quer seja para enviar cronogramas de aulas, avisos, divulgação de cursos, quer seja propriamente no ensino, por meio de compartilhamento de artigos científicos, livros etc.

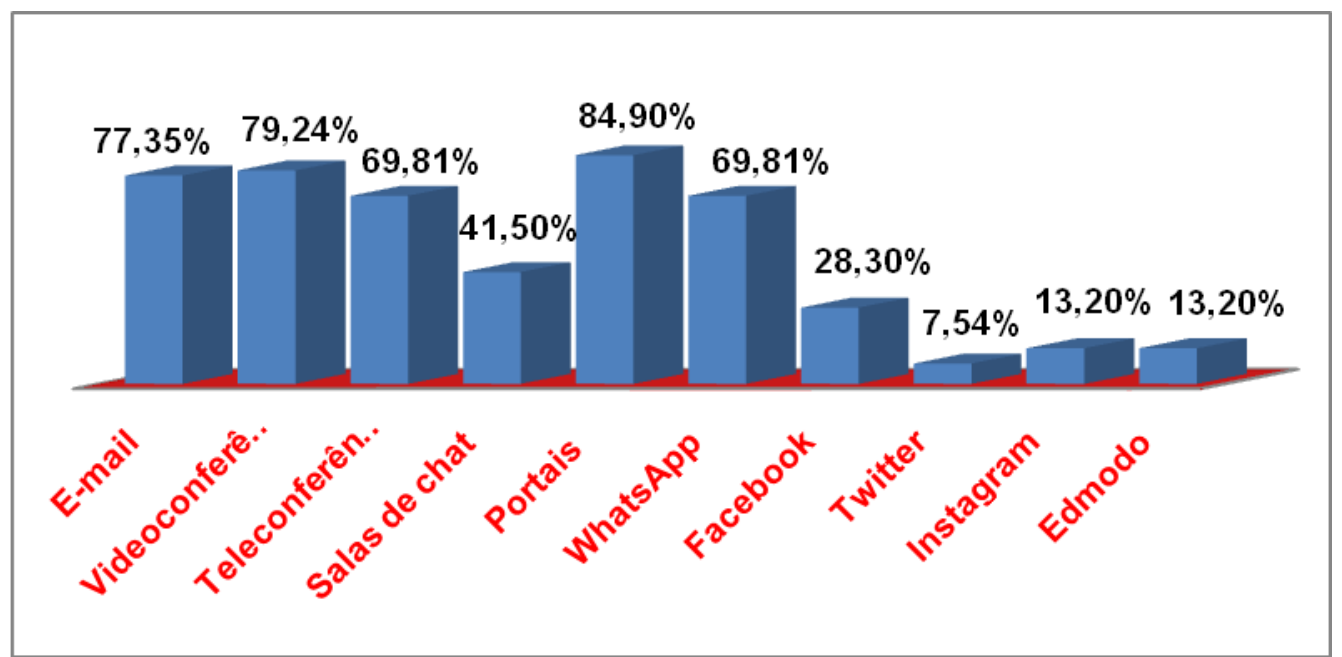

Figura 1: Tecnologias utilizadas por professores do curso de fisioterapia, Belém e Santarém, 2017

O pesquisador, na qualidade de entrevistador, entende que os entrevistados têm consciência da evolução do processo ensino-aprendizagem, 
e, com o incremento das novas tecnologias de comunicação na sociedade, a postura e o anseio dos discentes vêm sendo modificados a cada ano. A fala seguinte cita um dos mecanismos utilizados por eles no compartilhamento: "Muito boa, pois geralmente são passadas experiências em grupos, sugestões de sites voltados para o ensino superior" (PB 12).

Também se nota que os professores mais experientes procuram se adaptar à nova realidade, participando de oficinas, aprimoramentos e cursos voltados às metodologias ativas, o que leva a uma instigação do discente durante o aprendizado. Muitos compreendem e aceitam como verdade a busca por uma mudança na atitude e consciência dos conceitos do novo saber ensinar, pelo fato de lidarem com discentes mais críticos e que têm mais facilidade de entrar em contato com o conhecimento.

Por vezes, por meio de impressões dadas pelos entrevistados, foi notado que, mesmo diante dessa evolução social, muitos professores não participam desse novo aprendizado, em toda a sua dimensão, devido à falta de melhor acesso à rede mundial de comunicação, o que deveria, segundo a visão dos entrevistados, ser obrigação da instituição, conforme notamos na fala que segue: "apesar da evolução e da utilização das redes sociais para facilitar a comunicação docente, percebo que não ocorre esse compartilhamento; cada docente de forma individual vai atrás de seus dispositivos de aprendizagem." (PS 09)

Os entrevistados mostram compreender a importância de melhor qualificação pedagógica docente, por meio de capacitação stricto sensu e da efetiva participação em grupos de pesquisas, a fim de produzirem conhecimentos na academia, com a participação ativa dos discentes nesse processo.

Percebe-se que há um entendimento quanto às habilidades $\mathrm{e}$ competências do professor para ensinar, sendo listadas diversas qualidades que deve desenvolver para bem ensinar, o que se nota na fala dos entrevistados, representada pela transcrição da resposta:

Percebo que hoje há uma tendência de professores de diferentes áreas buscarem uma troca maior de conhecimentos, bem como integrá-los tanto para conhecimento próprio, quanto para assim repassá-los para os alunos. Não sinto resistência quanto a isso. (PB 03) 
Analisando as respostas dos entrevistados, nota-se uma tendência entre os professores de disseminar os conceitos de compartilhamento e sua importância entre os pares e os alunos. Porém, há desafios a superar, tal como o acesso à Internet que deve ser oferecido pela IES, liberando-o às redes sociais, no intuito de alimentar e divulgar assuntos inerentes ao aprendizado, conforme identificado na seguinte fala: "pensamos que a relação entre os pares deveria ser mais estreita, para que houvesse melhor compartilhamento pedagógico e de experiências que cada professor adquire profissionalmente" (PB 02).

Além disso, para aqueles que experimentaram ou têm a prática da inserção do compartilhamento através das mídias sociais, nota-se uma aprovação do seu uso, o que facilita a participação de todos os envolvidos, inclusive daqueles alunos que, em sala de aula, não conseguiriam se manifestar ou tirar dúvidas:

percebo maior interação e crescente disponibilidade no compartilhamento de materiais, o que fortalece o grupo como um todo, bem como cria oportunidades de autoavaliação, corresponsabilidade, coletividade e crescimento mútuo. Porém, isso ainda é uma realidade mais seleta, própria de quem tem mais proximidade pessoal, laços de amizade. (PB 34)

Comparadas as realidades de Belém e Santarém, os professores pesquisados se posicionaram de forma muito semelhante quanto às mudanças e às necessidades de aprimoramento e adaptação, mesmo trabalhando em condições bem diferentes, quer seja em número de professores alocados para os dois cursos, quer seja quanto à estrutura e ao apoio acadêmico.

Invariavelmente, percebemos que o estímulo para buscar novos aprendizados não é diretamente proporcional à qualificação pedagógica dos professores. A oportunidade de estar envolvidos com uma nova metodologia parece ser o motivo maior na busca de um novo saber.

Ao final, ao analisarmos as respostas dadas pelos docentes sobre esse tema, inferimos que a percepção que eles têm sobre as grandes mudanças metodológicas, pelas quais está passando o curso de fisioterapia da Uepa, faz que com busquem novas habilidades e competências para o fazer ensinar, o que, muitas vezes, ocorre por estímulo próprio ou, ainda, pelo apoio da instituição por meio de cursos de capacitação, vivências ou outros métodos pedagógicos. 
A principal limitação deste estudo reside na diferença da participação dos professores de Belém em relação a Santarém. Enquanto na capital a participação foi da maioria absoluta, em Santarém, o número de participantes ficou um pouco acima da metade, embora o pesquisador tenha se deslocado duas vezes a cidade e tenha contado com o apoio das lideranças para divulgar e solicitar aos professores que participassem, com diminuição da carga horária para os dias agendados.

\section{Considerações finais}

Os professores fisioterapeutas dos cursos de fisioterapia da Uepa de Belém e Santarém estão passando por mudanças profundas no processo de ensino-aprendizagem. Desde as recomendações das DCN de 2002, os cursos buscam implantar métodos mais atualizados de ensino para a formação de um profissional humanizado, participativo, questionador e que seja coparticipante de uma nova estruturação social.

Oriundo de uma formação tradicional, com foco no professor, sem muita participação do aluno na construção do conhecimento, o docente busca transformar não só a maneira de facilitar o conhecimento, mas, principalmente, a si próprio enquanto educador.

Por meio da qualificação pedagógica, com apoio pontual da instituição, e da realização de cursos de capacitação e aprimoramento, os professores têm se mostrado adeptos dessas transformações. Para eles, fazer parte de um novo contexto de ensino, no qual o aprendizado está centrado no aluno, tem estimulado as diversas gerações de professores do curso a se adaptar o mais rápido possível.

As metodologias ativas vêm a favor da construção de um novo profissional preconizado pelas DCN, e o compartilhamento de conhecimentos se tornou uma necessidade, para que o aluno seja totalmente estimulado a participar ativamente da construção do conhecimento. Investimento em estrutura e acesso livre à Internet nos muros da instituição parecem ser o início de uma nova atitude educacional. Além disso, proporcionar ao professor uma adaptação a essa realidade, associando a grande experiência que tem no ensino, é motivo suficiente para esse investimento. 
Para muitos docentes, o compartilhamento de informações e conhecimentos é de suma importância para o processo ensino-aprendizagem, principalmente, no contexto das metodologias ativas, porém, não há sistematização pela universidade em estimulá-lo de forma oficial e progressiva.

Estimular e possibilitar a criação de uma agenda eletrônica, quer seja por meio de um blog, quer por meio da utilização de uma plataforma disponível para o ensino, parece ser o início de uma nova prática de compartilhar conhecimentos e interesses entre alunos e professores. Tanto o blog quanto as plataformas em formato de diário podem ser atualizados pelas duas partes interessadas, disseminando em tempo real palestras, cursos, simpósios, publicações, aulas e outras atividades e novidades na área em comum.

Independentemente das realidades diferentes dos dois cursos de Belém e Santarém, o estímulo do professor parece ser o mesmo, porém, sem as mesmas oportunidades. Isso porque, embora tenham o mesmo projeto pedagógico, há diferenças em termos de quantitativo de professores alocados, tendo Belém quase o dobro do número de professores de Santarém, e de estrutura e oportunidades.

A falta de acesso às mídias sociais pela Internet da instituição e a ausência de experiências compartilhadas por outros professores acerca do uso das mídias sociais no ensino são exemplos das dificuldades enfrentadas por eles nesse contexto.

Conclui-se que, mesmo com diferença numérica de participantes na pesquisa, comparando-se Belém e Santarém, os resultados foram ricos em percepções na análise do conteúdo referente aos objetivos da pesquisa, tendo, ao final, alcançado cada um deles. As duas cidades apresentam diferenças em suas relações com os professores, o que vai desde o acesso com velocidades diferentes à Internet, até o apoio institucional à pesquisa. Com quase a metade do número de professores da capital, os professores de Santarém trabalham com a mesma matriz curricular, porém, com menor estímulo a atividades que completam o processo ensino-aprendizagem. Entretanto, a concepção da inovação no ensino e das mudanças no aprender é evidente e faz parte de sua rotina. 
Independentemente do estímulo, da diferença de velocidade da Internet, do número de professores alocados ou das peculiaridades de cada região, os docentes de Belém e Santarém apresentaram a mesma capacidade de lidar com a inovação e estão dispostos a adaptar o novo ao seu dia a dia.

Não aceitar a transformação da sociedade com influência direta na construção do conhecimento seria negar que o aluno deva ser mais participativo e deva ter uma atitude reflexiva na construção do saber. Reinventar uma atitude educacional passa pela transformação de conceitos, quebra de paradigmas e aquisição de novas habilidades e competências, em que todos os envolvidos no processo ensino-aprendizagem ganhem. 


\section{Referências bibliográficas}

ARIÈS, Philippe. História social da criança e da família. 2ªed. Rio de Janeiro: LTC; 2006.

BAHNER, D. P. et al. How we use social media to supplement a novel curriculum in medical education. Medical Teacher, v. 34, n. 6, p. 439-444, mar 2012.

BARDIN, L. Análise de conteúdo. São Paulo: Edições 70, 2016.

CAMPOS, C. J. Gomes. Método de análise de conteúdo: ferramenta para a análise de dados qualitativos no campo da saúde. Revista Brasileira de Enfermagem, v.57, n.5, p.611-614, set-out 2004.

CANZONIERI, A.M. Metodologia da pesquisa qualitativa na saúde. 2ª̂ed. Petrópolis: Vozes, 2011.

GADOTTI, M. Pedagogia: diálogo e conflito. 8ed. São Paulo: Cortez, 2008.

GOMES, A. P.; REGO, S. Transformação da educação médica: é possível formar um novo médico a partir de mudanças no método de ensinoaprendizagem. Revista Brasileira de Educação Médica, v. 35, n. 4, p. 557-566, set 2011.

HANSON, C. et al. Use and acceptance of social media among health educators. American Journal of Health Education, v.42, n.4, p.197-204, jul-aug 2011.

HILLMAN, T.; SHERBINO, J. Social media in medical education: A new pedagogical paradigm? Postgraduate Medical Journal, v.91, n.1080, p.544-545, sep 2015.

IVALA, E.; GACHAGO, D. Social media for enhancing student engagement: The use of Facebook and blogs at a University of Technology. South African Journal of Higher Education.v.26, n.1, p.152-167, jan 2012.

LEITE, F. C. L.; COSTA, S. M. S. Gestão do conhecimento científico: proposta de um modelo conceitual com base em processos de comunicação científica. Ciência da Informação, v.36, n.1, p.92-107, jan-abr 2007.

PROBST, G.; RAUB, S.; ROMHARDT, K. Gestão do conhecimento: os elementos construtivos do sucesso. Porto Alegre: Bookman Editora, 2009.

SCHARF, E. R. Conhecimento compartilhado nas universidades: o tácito e o explícito em sala de aula. Revista Eletrônica Sistemas e Gestão, v.3, n.3, p. 216-232, set-dez 2008.

TOMAÉL, M. I; ALCARÁ, A. R; DI CHIARA, I. G. Das redes sociais a inovação. Ciência da Informação. v.34, n.2, p. 93-104, mai-ago 2005.

VOZENILEK, J. et al. See one, do one, teach one: Advanced technology in medical education. Academic Emergency Medicine, v. 11, n. 11, p. 1149-1154, nov 2004. 